\title{
STUDY OF SOME HEALTH HAZARDS AMONG OPERATING THEATER PERSONNEL DUE TO EXPOSURE TO ANESTHETIC GASES (II)
}

\author{
By \\ Siha MS ${ }^{1}$, Farahat $\mathrm{SA}^{1}$, Rashed $\mathrm{LA}^{2}$ and Helmy $\mathrm{NM}^{1}$ \\ ${ }^{1}$ Department of Occupational and Environmental Medicine, ${ }^{2}$ Department of Biochemistry, \\ Faculty of Medicine, Cairo University. \\ Corresponding author: Siha MS: mona.siha@kasralainy.edu.eg
}

\begin{abstract}
Introduction: Anesthetics are essential materials used in hospitals to induce unconsciousness in patients prior to surgical procedures. The most commonly used agents are isoflurane, sevoflurane and halothane. Aim of work: To assess the health effects of exposure to anesthetic gazes focusing on hepatic and renal manifestations among operating room (OR) personnel. Materials and methods: Operating room (OR) personnel (184: 68 males and 116 females) were included in the study and compared with 192 (63 males and 129 females) from other departments staff of the same hospital mainly from internal medicine hospital and outpatient clinics. The studied groups filled a questionnaire including personnel, family, past and present histories. Liver and kidney function tests were examined. Plain urine samples were collected at the end of shift to test for $\beta_{2}$ microglobulin. Operating theaters were evaluated regarding the type of breathing circuits used whether open or closed, the type of anesthetic gases used, presence of air conditioning, and scavenging system. Isoflurane air level was measured using the organic method 103 by OSHA. Results: OR personnel experienced symptoms namely headache, tiredness, drowsiness, and decreased memory compared with their controls, without having statistical significance except for headache. There was a statistically significant increase in the level of ALP (Alkaline phosphatase), total bilirubin, urea, creatinine and $\mathrm{B}_{2}$ microglobulin among exposed when compared to the control group. Also AST (Aspartate transaminase), ALP, direct bilirubin, $\mathrm{B}_{2}$ microglobulin, urea and creatinine were higher among personnel using both open and closed circuits than in those using closed circuits only. The mean values of AST, ALP, total bilirubin, $\mathrm{B}_{2}$ microglibulin urea and creatinine were higher among personnel using isoflurane, sevoflurane and halothane (3 types of anesthetic gazes) more than those using isoflurane and sevoflurane or those using isoflurane only. The mean levels of urea and creatinine were statistically higher among surgeons when compared to
\end{abstract}


other groups. Conclusion: Personnel working in operating theaters are more at risk to develop disturbances in liver and kidney functions compared to the controls especially surgeons. Recommendations: Implementation of adequate and working scavenging system, air conditioning, use of closed circuits whenever possible, periodic checking of anesthetic air levels, periodic biochemical analysis for OR personnel, and replacement of any malfunctioning parts of anesthesia machine.

Key words: Liver function tests, Kidney function tests, Isoflurane, Sevoflurane and Operating room personnel.

\section{Introduction}

Starting from the 1960s, adverse health effects were observed among medical personnel who had been working with anesthetic gases. Exposure measurements that were taken in operating rooms during the clinical administration of inhaled anesthetics indicated that waste gases can escape into the room air from various components of the anesthesia delivery system. In addition, selected anesthesia techniques and improper practices also can contribute to the escape of waste anesthetic gases into the operating room atmosphere (Jaloszynski et al., 1999).

All personnel in surgical areas (anesthetists, surgeons, nurses, obstetricians and other operating room personnel) are exposed to volatile anesthetics. The amount of occupational exposure depends on waste gas scavenging devices and effective ventilation systems that circulate and replenish the air with the required frequency. Consequently, workers in areas adjacent to those where volatile anesthetics are used must also be considered at risk of exposure. It is generally believed that long-term exposure to small concentrations of volatile anesthetics could have adverse health effects (Aragones et al., 2015)

In general, operating room personnel reported effects of exposure to waste anesthetic gases like nausea, dizziness, headaches, tiredness, fatigue, exhaustion, irritability, drowsiness, loss of concentration, remembering difficulties, coordination and judgment problems, as well as infertility, miscarriages, birth defects, liver, kidney diseases and cancer (Chandrasekhar et al. 2006).

\section{All halogenated inhalational} anesthetics are associated with liver injury. Halothane, enflurane, isoflurane and desflurane are metabolized through the metabolic pathway involving cytochrome P-450 2E1 (CYP2E1) and produce trifluoroacetylated components; some of which may 
be immunogenic. The severity of hepatotoxicity is associated with the degree by which they undergo hepatic metabolism by this cytochrome: $(20 \%$ to $30 \%$ for halothane, $2 \%$ for enflurane, $1 \%$ for sevoflurane, and $0.2 \%$ or less for isoflurane and desflurane) and the metabolic products. However, liver toxicity is highly unlikely from sevoflurane as is not metabolized to trifluoroacetyl compounds (Safari et al., 2014). Hepatic damage by isoflurane is extremely rare and is attributed to an immune-mediated reaction, caused by oxidative biotransformation to reactive metabolites (Rahimzadeh et al., 2014).

Bito and Ikeda, 1996, performed a study on the liver functions of patients selected randomly to receive sevoflurane $(\mathrm{No}=50)$ or isoflurane $(\mathrm{No}=50)$ in a non blinded manner. Clinical laboratory studies for serum total and direct bilirubin, Aspartate aminotransferase (AST), Alanine aminotransferase (ALT), and Alkaline phosphatase (ALP) were performed before and after anesthesia. The levels of these enzymes were significantly higher than values before anesthesia.

Anesthesia can affect renal functions and body fluid regulation indirectly as well as directly. The direct effects of anesthesia which are dose and agent-dependent include effects on auto regulation of renal blood flow, alteration in the effect of anti diuretic hormone (ADH), and effects on tubular transport of sodium and organic acids (Burchardi and Kaczmarczyk, 1994). Some anesthetic drugs induce anti-inflammatory, antinecrotic, and anti-apoptotic effects on renal tissue (Motayagheni et al., 2017). Researchers found that isoflurane provides preconditioning protective effects through anti-inflammatory and anti-apoptotic actions in a rat model (kim et al., 2013). Sevoflurane did not impair renal concentrating ability in humans (Frink et al., 1994).

\section{Aim of work}

To assess the health effects of exposure to anesthetics gazes, focusing on hepatic and renal manifestations among operating room (OR) personnel.

\section{Materials and methods}

Study design: It is a cross sectional study.

\section{Place and duration of the study:}

The study was conducted at operating theaters, recovery rooms and surgical intensive care rooms in Kasr Al Ainy Hospitals. 
Some theaters use open and closed circuits for anesthesia which are: major and minor surgery, orthopedics, $4^{\text {th }}$ and $5^{\text {th }}$ floors pediatrics, ENT and ophthalmology theaters (number of working personnel $=96$ that represents $52 \%$ of the study sample), while other theaters use closed circuits only which are: neurosurgery, gynecology, cardiothoracic and urology theaters $(\mathrm{No}=88$ that represents $48 \%$ of the study sample).

Some theaters (neurosurgery and cardiothoracic) use isoflurane gas only (number of operating personnel $=58$, with a percentage of $31 \%$ ), some other theaters (ophthalmology and 4th floor pediatrics) use isoflurane, sevoflurane and occasionally halothane (No $=27$ with a percentage of $15 \%$ ), while the rest of theaters use isoflurane and sevoflurane (No $=99$ with a percentage of $54 \%$ ).

Study sample: The study was conducted among 198 operating room personnel in Kasr Al Ainy Hospitals (The whole working population who accepted to be included in the study).

The only inclusion criterion was regular working in operating rooms for the past 2 years.
The exclusion criteria were taking any cytotoxic drugs or exposure to any kind of ionizing radiation for the last 6 months before conducting the study.

Accordingly; 14 were excluded for being working less than 2 years, so the remaining were 184 operating room personnel (68 males and 116 females) exposed to anesthetic gases. Among them were the anesthetists $(\mathrm{No}=31(17 \%))$, surgeons $(\mathrm{No}=26$ $(14 \%)$ ), nurses (No $=82(45 \%))$, and workers $(\mathrm{No}=45(24 \%))$. During their work, operating room personnel were exposed to a complex mixture of anesthetic agents (halothane, isoflurane, sevoflurane, and previously nitrous oxide). The use of nitrous oxide has been stopped since 2008 .

A control group of matched 192 subjects (63 males and 129 females) was selected from other departments staff of the same hospital mainly from internal medicine hospital and outpatient clinics (doctors, nurses, workers and secretaries) with no history of occupational exposure to anesthetic agents, and not taking any cytotoxic drugs or exposed to ionizing radiation during the entire previous 6 months, and not having positive hepatitis markers. 


\section{Study methods:}

A ) The studied groups were subjected to the following:

1- A self designed face-to-face questionnaire, which included standard demographic data (age, gender) as well as medical history of diseases, exposure to X-rays, medication, lifestyle (smoking, alcohol), and occupational history (years of exposure, weekly exposure, hours, type of anesthetic used, operating theater design used for anesthesia and use of protective measures).

\section{2- Laboratory investigations:}

- Collection of blood samples: Venous blood was collected once from all the study and control group subjects. Blood samples were coded to avoid possible bias. The samples were transported on ice to the laboratory and were processed within $24 \mathrm{~h}$.

\section{-Liver function tests:}

The tests included serum AST, ALT, ALP, Bilirubin (total and direct)

\section{- Kidney function tests}

The tests included Urea and Creatinine.
The reference values of them are:

AST (Aspartate aminotransferase):

$$
\text { 10-40U/L }
$$

ALT (Alanine aminotransferase) :

\section{$10-55 \mathrm{U} / \mathrm{L}$}

ALP (Alkaline phosphatase) :

$45-115 \mathrm{U} / \mathrm{L}$

Bilirubin Total: $0.1-1 \mathrm{mg} / \mathrm{dl}$

Direct: $0-0.4 \mathrm{mg} / \mathrm{dl}$

Urea: $23-43 \mathrm{mg} / \mathrm{dl}$

Creatinine: $0.8-1.4 \mathrm{mg} / \mathrm{dl}$

B) In all studied theaters the following was done:

1) Description of the workplace: Air was conditioned by a laminar flow system with recirculation of $60 \%$ of exhausted air. The air flow entered through the upper parts of the walls and was evacuated at openings in the walls near the floor level, creating a laminar air flow. However in all operating rooms (ORs), the exhaust outlets of the anesthesia machines were not connected to a waste gas scavenging system.

2) Each operating theatre was checked for: -The type of breathing circuits used whether open or 
closed.-The type of anesthetic gases used.-Scavenging system: present or not.

\section{C ) Environmental measurement:} Isoflurane, sevoflurane and halothane are the only anesthetic gases currently used in Cairo University Hospitals, and isoflurane being the only gas used in all ORs, so it was selected for environmental monitoring. OSHA Organic Method 103 was used (OSHA, https://www.osha.gov/dts/sltc/methods/ organic/org103/org103.html).

\section{Consent}

An informed consent was obtained from each participant after clarifying the aim of the study and assuring their data privacy.

\section{Ethical approval}

The study protocol was approved by Occupational and Environmental Medicine Department Ethical Committee, Faculty of Medicine, Cairo University.

\section{Data management}

Data were coded and entered using the statistical package SPSS version 21.Data was summarized using mean and standard deviation for the quantitative variable. Comparison of quantitative variables was done using analysis of variance (ANOVA) with multiple comparisons post hoc test when comparing more than 2 groups and using unpaired $\mathrm{T}$ test when comparing 2 groups. Exact test was used instead when the expected frequency is less than 5. Correlation was done to test for linear relations between quantitative variables by Pearson correlation. p-values less than 0.05 were considered

\section{Results}

Isoflurane air level was higher than NIOSH Recommended Exposure Limit (RELs : 2ppm) ( Berry, 1999 and https://ehs.research.uiowa.edu/isofluraneanesthetic-gas-guidelines ) in most of the measured points, and that level was higher in theaters using dual open and closed circuits than in theaters using closed circuits only. Also the level was higher in points near the anesthesia machine and in recovery rooms than critical care rooms.

The mean levels of isoflurane at different points of measurements was $(5.23 \pm 4.76$ ppm), (3.57 $\pm 3.57 \mathrm{ppm})$ and $(3.51 \pm 3.19 \mathrm{ppm})$. 
Table 1: Frequency distribution of symptoms among operating room personnel.

\begin{tabular}{|l|c|c|c|c|c|}
\hline \multirow{2}{*}{} & \multicolumn{2}{|c|}{$\begin{array}{c}\text { Exposed } \\
\text { (No=184) }\end{array}$} & \multicolumn{2}{c|}{$\begin{array}{c}\text { Control } \\
\text { (No=192) }\end{array}$} & \multirow{2}{*}{ p value } \\
\cline { 2 - 5 } & No & $\%$ & No & \% & \\
\hline Headache & 75 & $40.80 \%$ & 49 & $25.50 \%$ & $\mathbf{0 . 0 0 2 *}$ \\
\hline Tiredness & 70 & $38.00 \%$ & 64 & $33.30 \%$ & 0.34 \\
\hline Drowsiness & 53 & $28.80 \%$ & 49 & $25.50 \%$ & 0.474 \\
\hline Decreased concentration & 25 & $13.60 \%$ & 63 & $32.80 \%$ & $<\mathbf{0 . 0 0 1 * *}$ \\
\hline Decreased remembering & 60 & $32.60 \%$ & 60 & $31.30 \%$ & 0.778 \\
\hline Tingling & 28 & $15.20 \%$ & 45 & $23.40 \%$ & $\mathbf{0 . 0 4 4} *$ \\
\hline
\end{tabular}

*: Statistically significant

**: Highly statistically significant

Table 1 showed that exposed group experienced symptoms namely headache, tiredness, drowsiness, and decreased concentration compared with their controls, without having statistical significance except for headache ( $\mathrm{p}$ value $=0.002$ ) However the control group showed statistically significant increase in decreased concentration and tingling.

Table 2: Mean \pm SD of biochemical values among operating room personnel.

\begin{tabular}{|l|c|c|c|}
\hline & $\begin{array}{c}\text { Exposed } \\
(\mathbf{N o = 1 8 4}) \\
\text { Mean } \pm \text { SD }\end{array}$ & $\begin{array}{c}\text { Control } \\
(\mathbf{N o = 1 9 2}) \\
\text { Mean } \pm \text { SD }\end{array}$ & p value \\
\hline AST (U/L) & $24.15 \pm 8.1$ & $23.56 \pm 4.18$ & 0.379 \\
\hline ALT (U/L) & $21.88 \pm 9.94$ & $21.56 \pm 4.13$ & 0.679 \\
\hline ALP (U/L) & $98.34 \pm 30.72$ & $70.42 \pm 13.08$ & $<\mathbf{0 . 0 0 1 * *}$ \\
\hline Bil (T) (mg/dl) & $0.74 \pm 0.29$ & $0.59 \pm 0.2$ & $<\mathbf{0 . 0 0 1 * *}$ \\
\hline Bil (D) (mg/dl) & $0.13 \pm 0.06$ & $0.13 \pm 0.06$ & 0.857 \\
\hline Urea (mg/dl) & $27.96 \pm 9.69$ & $17.04 \pm 2.88$ & $<\mathbf{0 . 0 0 1 * *}$ \\
\hline Creatinine ( $\boldsymbol{\mu g} / \mathbf{L})$ & $0.62 \pm 0.21$ & $0.53 \pm 0.16$ & $<\mathbf{0 . 0 0 1 * *}$ \\
\hline B microgl. (mg/dl) & $324.4 \pm 157.24$ & $165.38 \pm 38.43$ & $<\mathbf{0 . 0 0 1 * *}$ \\
\hline
\end{tabular}

**: Highly statistically significant AST: Aspartate aminotransferase ALP: Alkaline phosphatase
B2 microgl.: B2 microglobulin

ALT: Alanine aminotransferase

Bil (T): Total bilirubin Bil (D): Direct bilirubin 
Table 2 showed that there was a statistically significant increase in the level of ALP, total bilirubin, urea, creatinine and B2 microglobulin, among exposed when compared to control group. Mean direct bilirubin was the same in both groups.

\section{Table 3: Mean \pm SD of biochemical values among operating room personnel regarding type of gases used.}

\begin{tabular}{|l|c|c|c|c|}
\hline & \multicolumn{3}{|c|}{ Gases used } & p value \\
\hline & $\begin{array}{c}\text { Isoflurane } \\
(\text { No=58) } \\
\text { Mean } \pm \text { SD }\end{array}$ & $\begin{array}{c}\text { Isoflurane\& } \\
\text { Sevoflurane } \\
\text { (No=99) } \\
\text { Mean } \pm \text { SD }\end{array}$ & $\begin{array}{c}\text { Isoflurane, } \\
\text { Sevoflurane\& } \\
\text { Halothane } \\
\text { No=27) } \\
\text { Mean } \pm \text { SD }\end{array}$ & \\
\hline AST & $21.38 \pm 5.19$ & $25.11 \pm 6.89$ & $26.56 \pm 14.06$ & $\mathbf{0 . 0 1 7 *}$ \\
\hline ALT & $19.94 \pm 8.15$ & $23.1 \pm 7.23$ & $21.62 \pm 18.4$ & 0.156 \\
\hline ALP & $75.58 \pm 19.62$ & $104.14 \pm 28.73$ & $125.95 \pm 24.74$ & $<\mathbf{0 . 0 0 1 * *}$ \\
\hline Bil(T) & $0.71 \pm 0.34$ & $0.72 \pm 0.27$ & $0.85 \pm 0.21$ & 0.072 \\
\hline Bil(D) & $0.14 \pm 0.07$ & $0.13 \pm 0.05$ & $0.14 \pm 0.09$ & 0.301 \\
\hline B microgl. & $294.06 \pm 149.65$ & $335.99 \pm 154.6$ & $347.07 \pm 178.15$ & 0.197 \\
\hline Urea & $26.52 \pm 9$ & $28.33 \pm 9.97$ & $29.69 \pm 10.04$ & 0.319 \\
\hline Creatinine & $0.62 \pm 0.16$ & $0.6 \pm 0.19$ & $0.7 \pm 0.33$ & 0.073 \\
\hline
\end{tabular}

*: Statistically significant

AST: Aspartate aminotransferase

ALP: Alkaline phosphatase

Bil (D): Direct bilirubin
**: Highly statistically significant

ALT: Alanine aminotransferase

Bil (T): Total bilirubin

B2 microgl.: B2 microglobulin

Table 3 showed that the mean value of AST, ALP, total bilirubin, B2 microglibulin urea and creatinine were higher among personnel using isoflurane, sevoflurane and halothane more than those using isoflurane and sevoflurane or those using isoflurane only. This increase is statistically significant for AST and ALP. 
Table 4: Mean \pm SD of biochemical values among operating room personnel using closed and those using open and closed circuits.

\begin{tabular}{|c|c|c|c|}
\hline \multirow{2}{*}{} & \multicolumn{2}{|c|}{ Circuits } & \multirow{2}{*}{ p value } \\
\hline \multirow{2}{*}{ AST } & $\begin{array}{c}\text { Closed } \\
\text { (No=88) } \\
\text { Mean } \pm \text { SD }\end{array}$ & $\begin{array}{c}\text { Open \& Closed } \\
\text { (No=96) } \\
\text { Mean } \pm \text { SD }\end{array}$ & \\
\hline ALT & $24.049 \pm 6.765$ & $24.238 \pm 9.196$ & 0.875 \\
\hline ALP & $22.572 \pm 9.007$ & $21.255 \pm 10.73$ & 0.371 \\
\hline Bil(T) & $88.055 \pm 29.296$ & $107.764 \pm 29.051$ & $<\mathbf{0 . 0 0 1 * *}$ \\
\hline Bil(D) & $0.781 \pm 0.321$ & $0.696 \pm 0.25$ & $\mathbf{0 . 0 4 7 *}$ \\
\hline B microgl. & $300.003 \pm 151.025$ & $346.754 \pm 160.26$ & 0.561 \\
\hline Urea & $26.273 \pm 8.699$ & $29.506 \pm 10.323$ & $\mathbf{0 . 0 4 4 *}$ \\
\hline Creatinine & $0.608 \pm 0.158$ & $0.632 \pm 0.245$ & $\mathbf{0 . 0 2 2 *}$ \\
\hline
\end{tabular}

*: Statistically significant

AST: Aspartate aminotransferase

ALP: Alkaline phosphatase

Bil (D): Direct bilirubin
**: Highly statistically significant

ALT: Alanine aminotransferase

Bil (T): Total bilirubin

B2 microgl.: B2 microglobulin

Table 4 showed a statistically significant increase in the level of ALP, direct bilirubin, B2 microglobulin and urea among personnel using both open and closed circuits than in those using closed circuits only. 
Table 5: Mean \pm SD of biochemical values among operating room personnel according to different job categories.

\begin{tabular}{|c|c|c|c|c|c|}
\hline & \multicolumn{4}{|c|}{ Occupation } & \multirow[b]{2}{*}{ p value } \\
\hline & $\begin{array}{c}\text { Surgeon } \\
(\text { No=26) } \\
\text { Mean } \pm \text { SD }\end{array}$ & $\begin{array}{c}\text { Anesthetist } \\
(\mathrm{No}=31) \\
\text { Mean } \pm \text { SD }\end{array}$ & $\begin{array}{c}\text { Nurse } \\
(\text { No=82) } \\
\text { Mean } \pm \text { SD }\end{array}$ & $\begin{array}{c}\text { Worker } \\
(\text { No=45) } \\
\text { Mean } \pm \text { SD }\end{array}$ & \\
\hline AST & $24.6 \pm 5.71$ & $22.66 \pm 6.74$ & $23.26 \pm 6.45$ & $26.52 \pm 11.75$ & 0.107 \\
\hline ALT & $21.68 \pm 6.62$ & $21.71 \pm 8.35$ & $20.7 \pm 6.99$ & $24.28 \pm 15.49$ & 0.615 \\
\hline ALP & $103.11 \pm 24.6$ & $101.4 \pm 28.47$ & $94.01 \pm 31.88$ & $101.35 \pm 33.06$ & 0.331 \\
\hline $\operatorname{Bil}(T)$ & $0.69 \pm 0.23$ & $0.73 \pm 0.3$ & $0.74 \pm 0.29$ & $0.77 \pm 0.32$ & 0.724 \\
\hline $\operatorname{Bil}(D)$ & $0.13 \pm 0.06$ & $0.12 \pm 0.05$ & $0.14 \pm 0.07$ & $0.13 \pm 0.06$ & 0.745 \\
\hline $\mathrm{B}_{2}$ microgl. & $337.96 \pm 162.26$ & $305.35 \pm 144.07$ & $323.1 \pm 160.05$ & $332.05 \pm 161.67$ & 0.895 \\
\hline Urea & $31.67 \pm 12.15$ & $26.01 \pm 8.25$ & $26.07 \pm 7.66$ & $30.61 \pm 11.3$ & 0.039* \\
\hline Creatinine & $0.7 \pm 0.3$ & $0.54 \pm 0.17$ & $0.59 \pm 0.19$ & $0.68 \pm 0.16$ & $0.001 * *$ \\
\hline
\end{tabular}

*: Statistically significant

AST: Aspartate aminotransferase

ALP: Alkaline phosphatase

Bil (D): Direct bilirubin
**: Highly statistically significant

\section{ALT: Alanine aminotransferase}

Bil (T): Total bilirubin

B2 microgl.: B2 microglobulin

Table 5 showed that the mean values of urea and creatinine were statistically significantly higher among surgeons compared to other work groups.

The mean values of ALP was higher among surgeons and the mean values of AST, ALT and Total bilirubin were higher among workers although statistically non significant.

The current study showed that all measured laboratory measurements are positively correlated with duration of work (data was not tabulated).

as statistically significant.

\section{Discussion}

Adversehealth effects were observed among operating room personnel who were exposed to anesthetic gases (Jaloszynski et al., 1999). The aim of this study was to evaluate the health effects among workers employed as operating room personnel (anesthetists, surgeons, nurses, and workers) in Cairo University Hospitals (CUHs) and to assess the level of anesthetic gases in the air of operating theaters. 
When it came to the detection of air level of anesthetic gases, in our study one operating room was chosen to represent each operating theater, also isoflurane was chosen from the used gases to be measured as it is the one which is used in all theaters with or without other gases.

Our study revealed a statistically significant increase in headache and non significant increase in tiredness and drowsiness among exposed personnel compared to the control group, as shown in Table 1. This agreed with the results obtained by Shaker et al., (2011) on their work on 27 non smoking female nurses in some of the operating rooms in Cairo University Hospitals, who were exposed to a mixture of isoflurane and sevoflurane without the use scavenging system. They found a statistically significant increase in headache and drowsiness among exposed compared to control group, and this can be explained that both studies were done in the same hospital with the same conditions.

Also our work were similar to the results obtained by Al-Ashour et al., (2014), in their study done on 29 operating room personnel exposed to anesthetic gases in Al-Sadder medical city in Iraq and 13 unexposed control, they found that staff in ORs were more prone to headache and dizziness than non exposed staff.

To show certain health effects associated with acute and chronic exposure to nitrous oxide among the staff of the department of Anaesthesiology and Intensive Care at the Clinical Hospital in Shtip, Macedonia; Eftimova et al., 2017 detected a significant difference in several health effects between exposed and unexposed groups including headache, dizziness, nausea and vomiting, euphoria and tachycardia.

What about the effect of the type of anesthetic gases on liver functions? Our study showed an increase in the mean values of AST, ALT, ALP, bilirubin total and direct among exposed personnel compared to the control group, and this increase was statistically significant for ALP and total bilirubin as shown in Table 2. The mean of all measured parameters was within normal ranges. Our results were concomitant with the results obtained by Casale et al., (2014), in their study done on 119 operating room personnel (anesthetists, surgeons and nurses) exposed to halothane, isoflurane, enflurane and $\mathrm{N} 2 \mathrm{O}$ in ORs in Italy, where they found that AST, ALT, and 
total bilirubin were significantly higher among exposed than control group.

Also the current work was similar to that of Mansour et al., (2012), in their study on liver enzymes changes induced by anesthetic gazes between the stuffs of operation room and the stuff of surgery wards in Golestan hospital, Ahvaz; when a total of 46 persons, who worked in operating room more than 3 hours a day, 3 days a week, were chosen and compared with a control group; consisted of 46 of medical wards staff. Serum levels of AST, ALT, ALP, bilirubin (total and direct) were measured in each group and compared. All liver enzymes were significantly higher among the exposed group $(\mathrm{p}<0.05)$.

Our study revealed that most of liver function values (AST, ALP, bilirubin (total and direct)) were higher among personnel using isoflurane, sevoflurane and halothane as anesthetic gases, and this increase was statistically significant for AST and ALP as shown in Table 3. Our work matched with the study done by Prokes et al., (2009) on operating room personnel (surgeons, anesthetists and nurses) exposed to halothane, and control group working in a bank, which revealed that the mean values of AST and ALT were significantly higher among exposed medical personnel than in the control group. The significant increase in hepatic enzymes may be explained that the exposure was mainly to halothane which is the most hepatotoxic anaesthetic gas (Safari et al. 2014).

In a prospective study done of Casale and co-workers, 2014, they detected that health workers exposed to anesthetic gases show higher levels of AST and ALT, gamma GT and bilirubin levels compared to unexposed controls.

Also it is similar to the study done by Darling et al., (2000) which was done on 30 patients undergoing surgery with general anaesthesia where 15 received isoflurane and 25 received halothane. They found that serum level of AST was significantly higher among patients anaesthetized with halothane than in those anaesthetized with isoflurane.

Further analysis of the results regarding the relation between type of circuits used and liver functions; our study showed a statistically significant increase in the level of ALP, direct bilirubin, among personnel using both open and closed circuits than in those using closed circuits only (Table 4). This was approved with the results of 
the environmental study which revealed that isoflurane air level was higher in theaters using open and closed circuits than in those using closed circuits only.

Regarding the effect of different job categories on liver functions; our study revealed that the mean value of ALP was higher among surgeons and the mean values of AST and Total bilirubin were higher among workers although statistically non significant (Table 5). The increase of the ALP among surgeons can be explained by that surgeons are exposed to high air level of isoflurane than workers and are exposed during the whole length of the operation. Also workers had longer weekly exposure hours than nurses and anesthetists, why they had high level of total bilirubin. Prokes et al., (2009) study revealed that surgeons had high level values of AST and ALT activities compared to anesthetists and instrumenting nurses.

\section{When it comes to renal affection;} our study showed that there was a statistically significant increase in the level of urea, creatinine and B2 microglobulin, among exposed when compared to the control group (Table 2). This was in coincidence with the study done by Trevisan et al., 2003 on 61 exposed subjects in surgical areas and 43 non exposed control, where they found significantly increase in total urinary proteins among all exposed operating room personnel compared to control subjects. Also it was matched with the results obtained by Caciari et al., (2013) in their study on professional exposure to anesthetic gases among health workers where they found significant increase in serum creatinine in 145 exposed subjects compared to 89 non exposed controls.

But our results were opposite to what was found by Abdel-Latif and Elgammal (2003) where they didn't reveal any change in the level of serum creatinine, blood urea nitrogen (BUN), or creatinine clearance in patients anaesthetized with sevoflurane and isoflurane. This can be explained by that their studies were done on patients anaesthetized with sevo and iso, so the exposure was for a short period and not a long term exposure like in occupational exposure.

On studying the effect of type of circuit used and kidney functions, the current results showed that all kidney functions parameters were 
higher among personnel using open and closed circuits than in those using closed circuits only, and this increase was statistically significant for urea and B2 microglobulin (Table 4). This was supported by the environmental results which revealed that isoflurane air level was high in theaters using open and closed circuits than in those using closed circuits only .This concurred with the study done by Trevisan et al., 2003, where they found significantly increased total urinary proteins among all exposed operating room personnel, and being higher among personnel using open more than semiclosed circuits.

Regarding the type of anesthetic gases used and the kidney, the current study showed that the mean values of urea, creatinine and B2 microglibulin were higher among personnel using isoflurane, sevoflurane and halothane more than those using isoflurane only (Table 3), but this increase was not statistically significant. This could be explained that halothane have a toxic effect on the kidney than other anesthetic gazes (Safari et al. 2014).

Our work results were similar to Abdel-Latif and Elgammal (2003) study which was done in Assiut University Hospital which revealed an increase in blood urea and serum creatinine among patient anaesthetized with sevoflurane more than those anaesthetized with isoflurane, but this increase was not statistically significant.

However these results differed with the results obtained by Higuchi et al., (1998), where they found that there was no difference in serum urea, creatinine and urinary B2 microglobulin between patients anaesthetized with sevoflurane and those anaesthetized with isoflurane, this may be explained by that their study was done on patients for single exposure and not for cumulative occupational exposure like in our study. However they found that urinary $\mathrm{N}$-acetyl glucosamine (NAG) was higher among sevoflurane group than isoflurane group.

On studying the relation between the type of job and kidney functions; our work showed that the mean values of urea and creatinine were statistically significantly higher among surgeons compared to other work groups (Table 5). This could be explained that surgeons were always standing where air level of anesthetic gas is high. As regards anesthetists they didn't stand beside the patient for the whole duration of operation but they stand during 
induction, recovery from anesthesia, and when needed, but during the rest of the operation they sit watching the monitors at the periphery.

\section{Conclusion and recommendations}

In the current study, we found that personnel working in operating theaters were more at risk to develop health hazards related to exposure to waste anesthetic gases. The latter included nausea, tiredness, headache, dizziness, together with liver and kidney function derangements. These were related to the prolonged exposure to anesthetic gazes over years and working in operating rooms utilizing open anesthetic circuits rather than closed one, a factor that result in high operating room concentrations of anesthetic gases. Personnel exposed to halothane anesthetic gas had more affection to liver functions parameters than other gases. Surgeons and workers had the higher parameters of kidney affection.

In this study it was evident that isoflurane air level was higher than PELs in most of measured points at the studied operating theater.

Implementation of adequate scavenging of waste anesthetic gases with securing adequate functioning of air conditioning systems, regular and proper maintenance of anesthesia machines, the use of closed systems whenever possible, periodic measurement of anesthetic gases in the OR to ensure keeping them within the safe levels, periodic checkup of operating room personnel (doctors, nurses and workers) and prompt adequate recognition and treatment of any health problems.

\section{Conflict of interest}

The authors declared that there is no conflict of interest exists.

\section{Funding}

\section{None}

'The author would like to acknowledge all the personnel who participated in this study.

\section{References}

1. Abdel-Latif MM and Elgammal SA (2003): Serum fluoride ion and renal function after prolonged sevoflurane or isoflurane anaesthesia. Eg J Anaesth; 19:79-83.

2. Al-Ashour IAK, Abd-Ali DK, Fallah MA and Kteo IQ (2014): Effect of Inhaled Anesthetics Gases on Health Staff Health Status in AlNajaf City. International Journal of Scientific \& Technology Research; 3(12): 384-8.

3. Aragonés J, Ayora A, Ribalta A, Gascó A, Medina J et al., (2015) :Occupational exposure to volatile anesthetics: a systematic review. Occupational Medicine; 66:202-7. doi:10.1093/ occmed/kqv193.

4. Berry A (1999): Recommended Exposure 
Limits for Desflurane and Isoflurane. Anesthesia and Analgesia; 88 (6): 1424. doi: 10.1213/00000539-199906000-0004

5. Bito H and Ikeda K (1996): Renal and Hepatic Function in Surgical Patients after Low-Flow Sevoflurane or Isoflurane Anesthesia. Anesth Analg; 82:173-6.

6. Burchardi H and Kaczmarczyk G (1994): The effect of anesthesia on renal function. European Journal of Anaesthesiology; 11(3):1638. Available at: https://www.researchgate. net/publication/15149668_The_effect_of_ anaesthesia_on_renal_function

7. Caciari TM, Capozzella A, Tomei F, Fiaschetti M, Schifano MP, et al. (2013): Professional exposure to anesthetic gases in health workers: estimate of some hepatic and renal tests. La Clinica terapeutica; 164(1): 5-9.

8. Casale T, Caciari T, Rosati MV, Gioffrè PA, Schifano MP, et al. (2014): Anesthetic gases and occupationally exposed workers. Environ Toxicol Pharmacol; 37: 267-74.

9. Chandrasekhar M, Rekhadevi PV, Sailaja N, Rahman MF, Reddy JP, et al. (2006): Evaluation of genetic damage in operating room personnel exposed to anaesthetic gases. Mutagenesis; 21(4): 249-54.

10. Darling JR, Murray JM, McBride DR, Trinick TR and Fee JP (1997): Serum glutathione S-transferase concentrations and creatinine clearance after sevoflurane anesthesia. Anesthesia; 52:121-6.

11. Darling JR, Sharpe PC, Stiby EK, McAteer JA, Archbold GPR, et al. (2000): Serum mitochondrial aspartate transaminase activity after isoflurane or halothane anaesthesia. British Journal of Anesthesia; 85 (2): 195-8.

12. Eftimova B, Sholjakova M, Mirakovski D and Hadzi-Nikolova M ( 2017): Health Effects Associated With Exposure to Anesthetic Gas Nitrous Oxide-N2O in Clinical Hospital - Shtip Personel. J Med Sci ; 5(6): 800-4.

13. Frink EJ, Malan TP, Isner RJ, Brown EA, Morgan SE, et al. (1994): Renal concentrating function with prolonged sevoflurane or enflurane anaesthesia in volunteers. Anesthesiology; 80:1019-25.

14. Jałoszyn’ski P, Kujawski M, Wasowicz M, Szulc R and Szyfter K (1999): Genotoxicity of inhalation anesthetics halothane and isoflurane in human lymphocytes studied in vitro using the comet assay. Mutation Research; 439:199-206.

15. Higuchi H, Sumita S, Wada H, Ura T, Ikemoto T, et al. (1998): Effects of Sevoflurane and Isoflurane on Renal Function and on Possible Markers of Nephrotoxicity. Anesthesiology; 89(2): 307-22.

16. Kim M, Ham A and Kim JY (2013): The volatile anesthetic isoflurane induces ecto-5'nucleotidase (CD73) to protect against renal ischemia and reperfusion injury. Kidney Int; 84 : 90-103.

17. Mansoor S, Farhad S, Mohammad KA, Amin SM and Vahid N (2012): Comparison of liver enzymes change induced by halothane leakage of anesthetic machine between the stuffs of operation room and the stuff of surgery wards in Golestan hospital, Ahvaz. Biochem Cell Arch;12(1): 181-3.

18. Martin JL, Plevak DJ, Flannery KD, Charlton M, Poterucha JJ, et al. (1995): Hepatotoxicity after Desflurane Anesthesia. Anesthesiology; 83:1125-29.

19. Motayagheni N ,Phan S, Eshraghi C, Nozari A and Atala A ( 2017): A Review of Anesthetic Effects on Renal Function: Potential Organ Protection. Am J Nephrol; 46:380-9 .https://doi. org/10.1159/000482014 . Available at https:// www.karger.com/article/abstract/482014.

20. NIOSH (1992): Recommendations for occupational safety and health: Compendium of policy documents and statements. Cincinati, OH: U.S. Department of Health and Human Services, Public Health Service, Centers for Disease Control, National Institute for Occupational Safety and Health. DHHS (NIOSH) Publication No. 92-100.

21. OSHA (2000): Anesthetic gases: guidelines for 
workplace exposure. Occupational safety and health administration. Directorate for Technical support. Office of Science and Technical Assessment. Government Printing Office. Washington, DC.

22. OSHA: Available at: https://www.osha.gov/dts/ sltc/methods/organic/org103/org103.html

23. Safari S, Motavaf M, Seyed Siamdoust S and Alavian S (2014): Hepatotoxicity of Halogenated Inhalational Anesthetics. Iran Red Crescent Med J ; 16(9): e20153. doi: 10.5812/ ircmj.20153.

24. Rahimzadeh P, Safari S, Faiz SH and Alavian SM (2014): Anesthesia for patients with liver disease. Hepat Mon; 14(7):e20153. doi: 10.5812/hepatmon.19881

25. Sahin SH, Cinar SO, Paksoy I, Sut N and
Oba S (2011): Comparison between low flow sevoflurane anaesthesia and total intravenous anesthesia during intermediate duration surgery: effects on renal and hepatic toxicity. Hippokratis; 15 (1): 69-74.

26. Shaker DA, Samir AM, Hagag HA, Abd ElAal AA and Afify RA (2011): Cytogenetic Damage in Operating Room Nurses Exposed to Anesthetic Gases. Med J Cairo Univ; 79(1): 237-44.

27. Trevisan A, Venturini MB, Carrieri M, Giraldo M, Maccà I, et al. (2003): Biological indices of kidney involvement in personnel exposed to sevoflurane in surgical areas. Am J Ind Med; 44(5):474-80 . 
